\title{
Functional characterization of a defense-related class-III chitinase promoter from Lupinus albus, active in legume and monocot tissues
}

\author{
Dean Oelofse ${ }^{1,2}$, Inge Gazendam ${ }^{1}$, Adri Veale ${ }^{1}$, \\ Arnaud Djami-Tchatchou ${ }^{2}$, Dave Berger ${ }^{3}$, Ian Dubery ${ }^{2^{*}}$ \\ ${ }^{1}$ Agricultural Research Council - Vegetable and Ornamental Plants (ARC-VOP), Pretoria, South Africa \\ ${ }^{2}$ Department of Biochemistry, University of Johannesburg, Johannesburg, South Africa \\ e-mail: idubery@uj.ac.za \\ ${ }^{3}$ Department of Plant Science, Forestry and Agricultural \\ Biotechnology Institute (FABI), University of Pretoria, Pretoria,
}

South Africa

\begin{abstract}
A class-III chitinase promoter was isolated from Lupinus albus. The region $5^{\prime}$ to the coding sequence of the IF3 gene was amplified by gene walking and sequenced. The proximal $2.0 \mathrm{~kb}$ sequence contains a predicted promoter site, including a TATA box, near the ATG start site. To test for minimal sequences needed for promoter activity, the region was restricted into fragments of $1.81,1.51$ and $1.13 \mathrm{~kb}$ and cloned into the pDM327 vector, upstream from the bar-gus fusion gene for Biolistic ${ }^{\mathrm{TM}}$ transformation. Transformation of lupin embryos, bean callus tissue, maize embryos and Ornithogalum callus demonstrated promoter activity for all fragments. In silico analysis identified putative cis-acting elements in the $1.81 \mathrm{~kb}$ fragment that could be important in controlling gene expression. Fungal elicitor activated-, woundinducible- and ethylene responsive elements were present in the $1.51 \mathrm{~kb}$ fragment. Myb elements and CAAT boxes that regulate responses to environmental factors and modulate promoter efficiency were identified in the $1.81 \mathrm{~kb}$ fragment. The 1.51 and $1.81 \mathrm{~kb}$ fragments were inserted upstream of the gus gene into the pBI121 vector for Agrobacterium tumefaciens transformation of tobacco. Quantitative GUS assays indicated that the promoter fragments are functional in planta and inducible by defense-related signals, wounding, as well as chemical elicitation. All important elements essential for Bion inducibility are present on the shorter $(1.51 \mathrm{~kb})$ promoter fragment, but both $5^{\prime}$ distal and proximal cis-elements are required for full functionality. The $I F 3$ promoter is, thus, suitable for use in defense gene constructs prepared for the production of anthracnose resistant lupin.
\end{abstract}

\section{Keywords}

Biolistics Cis-elements Chitinase Lupin Pathogenesis-related Promoter Regulation

\section{Introduction}

Several species of lupins are cultivated in Mediterranean climate regions, since they can tolerate acidic and sandy soils and provide a crop rotation option for wheat (www.lupins.org) (Adhikari et al. 2013). Narrow-leafed lupin, Lupinus angustifolius is grown for the animal feed market as an alternative to soybean (Adhikari et al. 2013). Lupinus albus on the other hand is a species with a larger seed and higher protein content that is grown for the human health food market (Adhikari et al. 2009). 
Lupin production is however challenged by anthracnose disease, which can cause yield losses of up to $100 \%$ (Koch et al. 2002; Adhikari et al. 2013). Lupin anthracnose is caused by Colletotrichum lupini (previously classified as C. gloeosporioides, Nirenberg et al. 2002) which is able to infect both foliar tissues as well as pods of lupin species (Lotter and Berger 2005). Most accessions of L. albus are highly susceptible, and during the 1990s growers had to abandon production of this species in Western Australia and the Western Cape in South Africa due to the disease (Lotter and Berger 2005; Adhikari et al. 2009). Deployment of newly developed lines with increased resistance in Australian breeding programmes is hoped to result in a resurgence of production (Adhikari et al. 2013).

Current knowledge of the molecular responses of L. albus during anthracnose disease is very limited. Chitinases have been characterized as important plant defense enzymes in other plants (Grover 2012), and these represent a good starting point for the study of L. albus defenses. Chitinases hydrolyze the B-1,4-linkage between $\mathrm{N}$-acetylglucosamine residues of chitin, a structural polysaccharide in the cell wall of many fungi. Chitinases are carbohydrate active enzymes (CaZYs), and most plant chitinases are placed into two CaZY families, glycosyl hydrolase 18 and 19 (Collinge et al. 1993; Henrissat and Bairoch 1993; Grover 2012). They are pathogenesis-related (PR) proteins and are part of the defense arsenal of plants (Grover 2012). There are seven different classes, I to VII (Neuhaus 1999). Most of the class III chitinases occur extracellularly (Yeboah et al. 1998). Class III chitinases are classified as family 18 glycosyl hydolases (CAZypedia, http://www.cazy.org/GH18.html). Based on comparative nucleotide sequence analysis, Regalado et al. (2000) classified IF3 as a class III basic (Chib1) chitinase.

Upon fungal infection, a number of chitinase genes are induced in the plant (Roby et al. 1990). Purified chitinase extracts restricted fungal growth in vitro (Broekaert et al. 1988; Mauch et al. 1988; Verberg and Huynh 1991). Furthermore, chitinase transgenic plants with demonstrated increased expression levels were less susceptible to certain pathogens (Broglie et al. 1991; Jach et al. 1995).

Regalado et al. (2000) reported that the L. albus genome contains only one class III chitinase gene, which they termed IF3 (Intracellular Fluid 3), since the protein was detected in the apoplast. These authors demonstrated the expression of IF3 chitinase following infection with Colletotrichum lupini, suggesting that it is involved in plant defense, since there was an increase in the accumulation of IF3 mRNA, as well as the IF3 protein.

The induction of chitinases following fungal infection (Roby et al. 1990; Broglie et al. 1991; Jach et al. 1995; Regalado et al. 2000) suggest that chitinase gene expression is initiated by an inducible promoter. Thus, it was decided to isolate the lupin IF3 chitinase promoter to drive expression of genes that could potentially be used to enhance resistance of transgenic plants against fungal infection. The advantage of using an inducible promoter is that it would only be activated during anthracnose infection, and the protein would only be expressed when needed, resulting in a reduction in energy cost to the plant (Gurr and Rushton 2005).

The aim of this study was to isolate the L. albus IF3 promoter, followed by the analysis of the isolated IF3 DNA sequence for possible promoter sites and cis-acting controlling sequences (Azhakanandam et al. 2015). Subsequently, it was necessary to test for the minimal sequence needed to retain promoter activity, and to demonstrate that the promoter is functional in planta following biolistic transformation of a number of plant tissues and stable 
Agrobacterium tumefaciens-mediated tobacco transformation with the promoter:gus constructs.

\section{Materials and methods}

\section{Genome walking, cloning and sequencing of promoter constructs}

DNA was extracted from leaf tissue of lupin seedlings using a DNeasy Plant Mini Kit (Qiagen, Venlo, Netherlands. Genome walking upstream from the 5'-end of the IF3 gene was performed using the GenomeWalker ${ }^{\mathrm{TM}}$ kit (Takara, Clontech, Mountain View, CA, USA). DNA $(2.5 \mu \mathrm{g})$ was restricted at $37^{\circ} \mathrm{C}$ with DraI, EcoRV, PvuII and StuI supplied with the GenomeWalker ${ }^{\mathrm{TM}}$ kit (Takara, Clontech, Mountain View, CA, USA), according to standard procedures (Sambrook et al. 1989). Ligations of each set of cleaned-up and restricted DNA to the GenomeWalker ${ }^{\mathrm{TM}}$ adaptors was subsequently performed.

Two gene-specific primers (GSP), one for the primary PCR reaction (GSP1) and one for the secondary PCR reaction (GSP2), were designed within the 5' end of the IF3 sequence based on the cDNA sequence deposited in Genbank Y16415: GSP1: 5'-

CTTCCAGCACCACCACCAAGTGAG-3' and GSP2: 5'GCCAGCAGCATTGGACAACTTGAA-3'.

PCR amplification conditions included an initial denaturation step of $95{ }^{\circ} \mathrm{C}$ for $1 \mathrm{~min}$. This was followed by 35 cycles with denaturation at $95{ }^{\circ} \mathrm{C}$ for $30 \mathrm{~s}$ and annealing at $68^{\circ} \mathrm{C}$ for $6 \mathrm{~min}$. A final extension step at $68^{\circ} \mathrm{C}$ for $15 \mathrm{~min}$ was included. StuI digests yielded a $4.2 \mathrm{~kb}$ band that was further analysed. PCR products were re-amplified using the Expand Long Distance Template Taq polymerase (Roche, Mannheim, Germany) and extracted from a $1 \%$ $(w / v)$ agarose gel, using the QIAquick Gel Extraction kit (Qiagen, Venlo, Netherlands, following electrophoresis of the PCR products.

PCR products were ligated into the pGEM-T Easy vector (Promega, Madison, WI, USA) and transformed into Escherichia coli DH5 $\alpha$ competent cells. Isolation of plasmid DNA from $E$. coli was done using the Qiaprep Mini plasmid purification kit (Qiagen, Venlo, Netherlands). Sequencing of the pGEM-StuI-4.2 bp (pGEM:4.2 kb) construct was by Microsynth (Balgach, Switzerland). The sequence data obtained for the $4.2 \mathrm{~kb}$ IF3 promoter-containing fragment (GenBank accession number KP981368) was compared to known sequences in the GENBANK database (http://www.ncbi.nlm.nih.gov/Genbank/).

\section{Identification of promoter sites and Cis-regulatory elements}

The Berkeley Drosophila Genome Project (BDGP): Neural Network promoter prediction site was used to predict possible promoter sites, including the TATA boxes, within the isolated $4.2 \mathrm{~kb}$ fragment (http://www.fruitfly.org/seq_tools/promoter.html/).

In order to identify putative defense-related cis-elements in the promoter area of IF3, a plant database on $c i s$-acting regulatory elements (PlantCARE, http://intra.psb.ugent.be:8080/PlantCARE; Lescot et al. 2002) was utilised. PlantPAN (http://PlantPan.mbc.nctu.edu.tw; Chang et al. 2008) and PLACE (http://www.dna.affrc.go.jp / PLACE; Higo et al. 1999) were also consulted. The $1.81 \mathrm{~kb}(-1800 \mathrm{bp})$ promoter sequence upstream of the predicted start codon (ATG) was chosen since most plant promoters display cis-elements within this region (New et al. 2015). 


\section{Cloning of promoter fragments into the pDM327 vector}

The putative promoter fragments were cloned into the pDM327 vector (Kamo et al. 2000) for Biolistic $^{\mathrm{TM}}$ transformation experiments to test for promoter activity in various plant tissues. The $2.18 \mathrm{~kb}$ IF3 fragment was PCR re-amplified from pGEM: 4.2Promoter using primers designed to the $4.2 \mathrm{~kb}$ fragment. The sense primer (RePromP2: 5'-

CAAATCTTTGAGCCTAACAGTATACAGAGATGAG-3') was designed to match the promoter sequence. The antisense primer (RePromP1: 5'-

GCGCGGATCCGTTTGTAGCTATATTCCAAGTTGT-3') was designed so that a BamHI site (bold underlined) was incorporated at the $5^{\prime}$-end of the primer to facilitate cloning of the PCR product into the BamHI site of pDM327. The annealing step was at $60{ }^{\circ} \mathrm{C}$ for $90 \mathrm{~s}$ and the pGEM:4.2Promoter plasmid DNA was used as a template in this PCR reaction.

DNA fragments $(2.18 \mathrm{~kb})$ were gel extracted and cloned into the pGEM-T Easy vector, resulting in a clone termed pGEM: 2.2Promoter. Truncated promoter-containing fragments were released from the pGEM:2.2Promoter plasmid with different restriction enzyme combinations: $N c o$ I and BamHI to yield a $1.817 \mathrm{~kb}$ fragment, $N$ siI and BamHI to yield a $1.519 \mathrm{~kb}$ fragment, and $B g l \mathrm{II}$ and $B a m H I$ to yield a $1.138 \mathrm{~kb}$ fragment. In all three cases the restricted DNAs were subjected to a Klenow DNA polymerase I large fragment fill-in step, before being restricted with BamHI.

In pDM327 the CaMV 35S promoter had been cloned into the vector upstream from the bargus translational fusion gene as a HindIII/BamHI fragment. This was substituted with the IF3 promoter-containing fragments. The pDM327 was restricted with HindIII and subjected to a Klenow polymerase fill-in step before being restricted with the $B a m H I$ restriction enzyme to remove the CaMV $35 \mathrm{~S}$ promoter fragment. The three IF3 promoter-containing blunt end BamHI fragments were then cloned separately into the pDM327 vector upstream from the bar-gus translational fusion gene. The resulting constructs pDM327:Prom1.8, pDM327:Prom1.5 and pDM327:Prom1.1 were tested for promoter activity using Biolistic ${ }^{\mathrm{TM}}$ transformation of plant tissue and staining for GUS activity.

\section{Biolistic $^{\mathrm{TM}}$ transformation of plant tissue to test for promoter activity}

The QIAfilter Plasmid Mega kit (Qiagen, Venlo, Netherlands) was used for the preparation of pDM327neg, pDM327, pDM327:Prom1.8, pDM327:Prom1.5 and pDM327:Prom1.1 plasmid DNA. The Biolistic Particle Delivery System, model PDS-1000/He (Bio-Rad, Hercules, CA, USA) was used for transformation.

Ornithogalum (A2/ Rolou) callus (a South African Ornithogalum breeding line, a result from a cross between $O$. dubium and $O$. thyrsoides), lupin (L. albus) immature embryo tissue, bean (Phaseolus vulgaris) callus tissue and maize (Zea mays) immature embryos were prepared. The latter was obtained from Dr. M O'Kennedy, CSIR Biosciences, Pretoria, South Africa.

The pDM327:Prom1.1, pDM327:Prom1.5 and pDM327:Prom1.8 plasmid DNA was used for the Biolistic ${ }^{\mathrm{TM}}$ transformation of the plant tissue. The positive control used was the pDM327 plasmid DNA (contains the CaMV 35S promoter upstream from the bar-gus translational fusion gene), and the negative control was pDM327neg plasmid DNA (no promoter upstream from the bar-gus translational fusion gene). Biolistic ${ }^{\mathrm{TM}}$ transformation of plant tissue was performed in triplicate for each of the constructs using the protocol described in De Villiers et al. (2001). 
After the bombardment of plant tissue, the material was placed in the dark at $26{ }^{\circ} \mathrm{C}$ for 2 days. Each plate was then stained with $1.0 \mathrm{~mL}$ of X-Gluc (5-bromo-4-chloro-3-indolyl $\beta$-Dglucuronide name) stain solution. The stained tissues were incubated overnight in the dark at $37^{\circ} \mathrm{C}$. The numbers of blue spots appearing were recorded and results photographed.

\section{Agrobacterium-mediated transformation of tobacco}

The pBI121-neg construct was prepared by excising the CaMV promoter from $\mathrm{pBI} 121$ to serve as a negative control during promoter studies of transformed tobacco. pBI121 plasmid DNA was digested with BamHI and HindIII, blunted with Klenow enzyme, the appropriate fragment recovered from an agarose gel using the QIAquick gel extraction kit (Qiagen, Venlo, Netherlands) and self-ligated using T4 DNA ligase according to standard protocols (Sambrook et al. 1989). The $1.51 \mathrm{~kb}$ and $1.81 \mathrm{~kb}$ promoter fragments were prepared from the respective pDM327 plasmids with $N$ siI/BamHI and $N c o I / B a m H I$, respectively, and ligated to the similarly prepared pBI121 vector. Ligation reactions were transformed into competent $E$. coli DH5 $\alpha$ cells and positive transformants selected on LB agar plates containing $50 \mu \mathrm{g} / \mathrm{mL}$ kanamycin. Restriction enzyme analysis and PCR screening of putative transformants were performed to identify true recombinants. The Expand Long template PCR (Roche, Mannheim, Germany) system was used to amplify the promoter fragments from recombinant pBI121:Prom1.5 and pBI121:Prom 1.8 constructs using the M13Rev (5'-CAG GAA ACA GCT ATG AC-3') and GUS sequencing primers (5'-TCA CGG GTT GGG GTT TCT AC-3'). The products were separated by agarose gel electrophoresis and the bands of interest sequenced (Inqaba Biotech, Pretoria, South Africa).

Chemically competent $A$. tumefaciens LBA4404 cells were transformed with the different pBI121-constructs by freeze-thaw and selection on LB agar plates containing $50 \mu \mathrm{g} / \mathrm{mL}$ each of rifampicin and kanamycin. Several transformed colonies were obtained for each of the pBI121 constructs and PCR screening indicated the expected amplified products. One clone of each construct was selected for tobacco transformation. Sterile disks of in vitro propagated Nicotiana tabacum (cv. LA Burley) leaves were submerged under suspensions of $A$. tumefaciens LBA4404 transformants in Murashige and Skoog (MS) medium with an $\mathrm{OD}_{620}$ of 0.8 , blotted dry and placed on MS-agar plates. After $48 \mathrm{~h}$ incubation in a growth room, the disks were subcultured onto regeneration medium (MS-agar containing $0.5 \mathrm{mg} / \mathrm{L}$ indole acetic acid, $1 \mathrm{mg} / \mathrm{L}$ benzyl adenine, $100 \mathrm{mg} / \mathrm{L}$ kanamycin and $250 \mathrm{mg} / \mathrm{L}$ cefotaxime). The leaf disks were subcultured to fresh regeneration medium at day 17 and day 32, where after individual shoots were transferred on day 44 to MS agar $\left(\right.$ kanamycin $^{100}$ cefotaxime $^{250}$ ) for rooting. Plantlets were maintained on MS agar (kanamycin ${ }^{100}$ Cefotaxime $^{250}$ ), with subculturing every 1 to 2 months, until contamination by A. tumefaciens had been eliminated, where after cefotaxime was omitted from the culture medium.

Plant genomic DNA was isolated from in vitro leaf disks using the CTAB extraction method and isopropanol precipitation (Murray and Thompson 1980). PCR screening using the M13Rev, NOSPolyA (5'-GAT AAT CAT CGC AAG ACC GGC AAC-3') and Gus sequencing primers and the nptII primers (NPTII-L (5'-GAG GCT ATT CGG CTA TGA CTG-3') and NPTII-R (5'-ATC GGG AGC GGC GAT ACC GTA-3')) were performed according to standard protocols. Positive controls containing plasmid DNA of the respective pBI121 constructs and negative water controls were included.

Leaf disks from each in vitro transgenic tobacco line were histochemically stained for GUS activity in GUS staining buffer [0.521 mg/mL X-Gluc in $100 \mathrm{mM} \mathrm{NaPO}_{4}$ buffer, $\mathrm{pH} 7.0$; 
10 mM EDTA; $0.1 \%$ Triton X-100; $0.5 \mathrm{mM}$ K-ferricyanide; $0.5 \mathrm{mM}$ K-ferrocyanide] and the chlorophyll bleached with $70 \%$ ethanol. The leaf disks were screened for the presence of dark blue spots.

\section{GUS expression assays of transgenic tobacco induced by elicitors}

Leaf disks were treated with various elicitors to induce expression of GUS by the 1.51 and $1.81 \mathrm{~kb} I F 3$ promoter fragments. These included Bion (acibenzolar- $S$-methyl benzo(1,2,3)thiadiazole-7-carbothioic acid $S$-methyl ester) $(200 \mu \mathrm{M}$, Syngenta, South Africa), sodium salicylate (400 $\mu \mathrm{M}$, Sigma Aldrich, Germany) and ethepon (3.3 mM, Sigma Aldrich, Germany) in $1 / 4$ strength MS medium ( $\mathrm{pH} 5.8$ ), wounding by pinching each leaf disk four times with a tweezer, and $1 / 4 \times \mathrm{MS}(\mathrm{pH}$ 5.8) as control. Ten mm diameter leaf disks were prepared from three biological replicates ( $3 \mathrm{~T} 0$ clones of each event), 40 disks per plant, of greenhouse grown plants of a single selected transgenic line of each construct. The discs were floated on top of the respective elicitor solutions, with the abaxial side of the leaf facing down, at $25^{\circ} \mathrm{C}$ for $24 \mathrm{~h}$ or $48 \mathrm{~h}$ with continuous illumination.

Ten mm leaf disks were homogenised with carborundum C-400 and extracted with extraction buffer $(1: 2 \mathrm{~m} / \mathrm{v})$ (Jefferson et al. 1987) for $1 \mathrm{~h}$ on ice. The supernatant was cleared from plant debris by centrifugation and the protein concentration determined (Bradford 1976).

Supernatants $(100 \mu \mathrm{L})$ were assayed for GUS activity by mixing it with $400 \mu \mathrm{L}$ assay buffer in a total volume of $500 \mu \mathrm{L}$. Reactions were incubated at $37^{\circ} \mathrm{C}$, and $100 \mu \mathrm{L}$ aliquots removed at 40,80 and $120 \mathrm{~min}$ and added to $400 \mu \mathrm{L}$ stop buffer $\left(0.2 \mathrm{M} \mathrm{Na}_{2} \mathrm{CO}_{3}\right)$. Fluorescence of these samples was measured in duplicate with a Fluoroskan Ascent FL microplate reader (Thermo Fischer Scientific, Waltham, MA USA) (excitation $355 \mathrm{~nm}$, emission $460 \mathrm{~nm}$ ) in black microwell plates.

A standard curve of 4-methyl umbelliferone (4-MU) ranging from 0 to $10 \mu \mathrm{M}$ in stop buffer was constructed to determine the linear range of the fluorometric assay for GUS. The increase in relative fluorescence $(\mathrm{RF})$ against time $(\mathrm{min})$ was determined and the GUS activity values were calculated and expressed as pmol 4-MU released/ $\mathrm{min} / \mathrm{mg}$ protein. Statistical analyses were performed using the Fisher's protected least significant difference test using the statistical program GenStat (2011).

\section{Results}

\section{Cloning and sequencing of the $4.2 \mathrm{~kb}$ promoter region of lupin IF3 chitinase}

The $\sim 4.2 \mathrm{~kb}$ insert in the plasmid pGEM-4.2Promoter (pGEM-StuI-4.2 kb) cloned from $L$. albus by genome walking was sequenced (GenBank accession number KP981368). As expected, the 3'-end of the sequence corresponded to the 5'-end of the L. albus chitinase III gene reported in Regalado et al. (2000), from the ATG to the gene-specific primer used for the secondary PCR (GSP2) (Fig. S1). BLASTN/X analysis of the $4.2 \mathrm{~kb}$ sequence against the GenBank database indicated that it comprised two sections - a 5' section of approximately $2.2 \mathrm{~kb}$ that contained open reading frames. It is likely that the $5^{\prime}$ section containing ORFs code for exon(s) of part of a gene upstream of the IF3 gene in L. albus, and was not further investigated in this study. BLASTN/X analysis of the $3^{\prime}$ end of the $4.2 \mathrm{~kb}$ fragment (nucleotides 2100-3960) showed no significant nucleotide identity to sequences in the Genbank database, lacked any ORFs, and was, thus, likely to contain the promoter and transcriptional regulatory regions of the lupin IF3 chitinase gene. 
Bioinformatics analysis (http://www.fruitfly.org/seq_tools/promoter.html/) was used to predict core promoter elements to assist with the choice of regions for nested deletion analysis. Three putative core promoter regions $(-1407$ to $-1357,-937$ to -887 and -41 to $-90)$ were predicted on the $3^{\prime}$ region that did not contain ORFs, with the most likely core promoter region closest to the ATG (position +1 to +3 ) of the chitinase gene (Porto et al. 2014) (i.e. corresponding to positions -90 to -41 ). These regions were therefore included for nested promoter deletion analysis (Fig. S2).

\section{Cloning of nested 1.81, 1.51 and $1.13 \mathrm{~kb}$ lupin $I F 3$ chitinase promoter-GUS fusions}

The $2.18 \mathrm{~kb}$ IF3 promoter-containing fragment was re-amplified from pGEM:4.2Promoter using primers RePromP2 and RePromP1, designed to the 5'- and 3'-ends, and cloned into the pGEM-T Easy vector to produce the pGEM:2.2Promoter. Restriction enzyme (EcoRI) digestion of the recombinants yielded the expected $2.18 \mathrm{~kb}$ promoter-containing fragment. The pGEM:2.2Promoter clone was sequenced and aligned to the pGEM:4.2Promoter sequence, and was found to be identical (data not shown).

To identify functional promoter regions within the isolated putative promoter fragment, deletion fragments were fused to the gus reporter gene to determine the minimal sequence needed to retain promoter activity (Bustos et al. 1989). Following this approach, restriction digests with NcoI/BamHI, NsiI/BamHI and BglII/BamHI (Fig. S3) yielded the promotercontaining fragments of $1.81 \mathrm{~kb}, 1.51 \mathrm{~kb}$ and $1.13 \mathrm{~kb}$, respectively, as shown in Fig. S2.

To create the gene constructs for use of $\beta$-glucuronidase (GUS) as reporter gene (Thomasset et al. 1996), the three fragments of the IF3 promoter-containing sequences were cloned separately upstream from the bar-gus translational fusion gene in the pDM327 vector by replacement of the CaMV 35S promoter (Fig. S4). The correct clones were confirmed by SalI restriction digests: clones pDM327:Prom1.1, pDM327:Prom1.5 and pDM327:Prom1.8 yielded the expected $1.46 \mathrm{~kb} / 1.84 \mathrm{~kb} / 2.14 \mathrm{~kb}$ fragments containing the respective $1.13 \mathrm{~kb} /$ $1.51 \mathrm{~kb} / 1.81 \mathrm{~kb}$ promoter-containing fragments (data not shown).

\section{Transient transformation of dicot and monocot plant tissues with nested lupin IF3 chitinase promoter-GUS fusions}

Biolistic $^{\mathrm{TM}}$ transformation has proven to be successful in monocotyledonous plants. It yields rapid results for transient expression and the high level of B-glucuronidase (GUS / uidA) expression enables rapid histochemical screening of transformants for transgene activity (Cornejo et al. 1993). Thus, the information needed, i.e. whether the IF3 promoter-containing DNA fragment isolated from $L$. albus has promoter activity, and whether promoter activity could be observed in both dicots and monocots, could be obtained rapidly using Biolistic ${ }^{\mathrm{TM}}$ transformation.

The pDM327:Prom1.1, pDM327:Prom1.5 and pDM327:Prom1.8 plasmid DNA was used for the Biolistic ${ }^{\mathrm{TM}}$ transformation of the Ornithogalum- and bean callus tissues, as well as immature maize - and lupin embryos. The positive control used in the experiment was the pDM327 plasmid DNA (containing the CaMV 35S promoter upstream from the bar-gus translational fusion gene), and the negative control was pDM327neg plasmid DNA (no promoter upstream from the bar-gus translational fusion gene). After histochemical staining, following the Biolistic ${ }^{\mathrm{TM}}$ transformation of the various plant tissues, GUS-positive spots were 
observed and counted. Figure 1 shows the results obtained with the $1.13 \mathrm{~kb}$ IF3 promotercontaining fragment, with summarized data for all the fragments in Table 1.
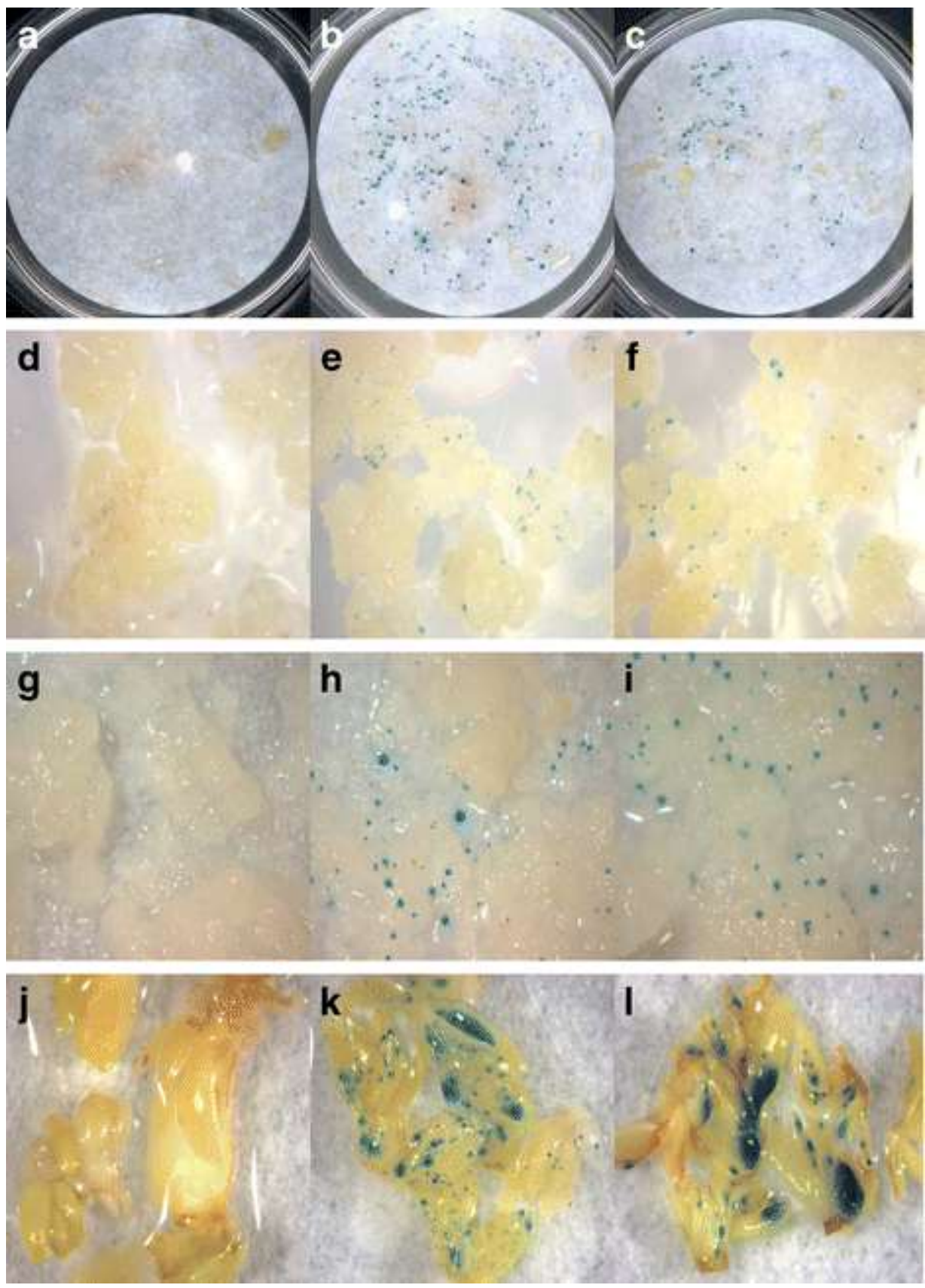

Fig. 1 : Transient GUS expression following Biolistic ${ }^{\mathrm{TM}}$ transformation of Ornithogalum callus tissue, maize immature embryo tissue, bean callus cultures and immature lupin embryo tissue. a: Ornithogalum callus tissue using the pDM327 neg construct (negative control), b: using the pDM327 construct (positive control) under the control of the Cauliflower Mosaic Virus (CaMV) 35S promoter and c: using the pDM327:Prom 1.1 construct containing the $1.13 \mathrm{~kb}$ class-III chitinase (IF3) promoter-containing fragment isolated from Lupinus albus. d: Maize immature embryo tissue using the pDM327 neg construct (negative control), e: the pDM327 construct (positive control) under the control of the CaMV 35S promoter and f: using the pDM327:Prom 1.1 construct. g: Bean callus cultures using the pDM327neg construct (negative control), h: the pDM327 construct (positive control) under the control of CaMV 35S promoter and $\mathbf{i}$ : using the pDM327:Prom 1.1 construct. $\mathbf{j}$ : Lupin immature embryo tissue using the pDM327 neg construct (negative control), $\mathbf{k}$ : the pDM327 construct (positive control) under control of the CaMV 35S promoter and $\mathbf{I}$ : using the pDM327:Prom 1.1 construct 
Table 1: GUS activity results from transient Biolistic ${ }^{\mathrm{TM}}$ transformation of the Ornithogalum - and bean callus as well as maize and lupin immature embryos using the nested lupin IF3 (chitinase III) promoter-GUS fusions

\begin{tabular}{lllllll}
\multicolumn{1}{c}{ Construct } & \multicolumn{1}{c}{$\begin{array}{c}\text { Promoter } \\
\text { fragment }\end{array}$} & \multicolumn{1}{c}{$\begin{array}{c}\text { Average number of blue spots per treatment } \\
\text { Ornithogalum } \\
\text { callus }\end{array}$} & \multicolumn{1}{c}{$\begin{array}{c}\text { Bean } \\
\text { callus }\end{array}$} & \multicolumn{1}{c}{$\begin{array}{c}\text { Immature maize } \\
\text { embryos }\end{array}$} & \multicolumn{1}{c}{$\begin{array}{c}\text { Immature lupin } \\
\text { embryos }\end{array}$} \\
pDM327neg & None & 0 & 0 & 0 & 0 & Medium* \\
pDM327 & CaMV35S & $272 \pm 157$ & $311 \pm 93$ & $397 \pm 136$ & Medium* \\
pDM327:Prom1.1 & $1.13 \mathrm{~kb}$ if3 & $208 \pm 105$ & $552 \pm 243$ & $220 \pm 14$ & High* $^{*}$ \\
pDM327:Prom1.5 & $1.51 \mathrm{~kb}$ if3 & $136 \pm 32$ & $468 \pm 266$ & $284 \pm 14$ & Medium* $^{*}$
\end{tabular}

*Relative GUS activity per treatment was visually assessed since the lupin tissue stained blue with large spots due to the high level of GUS expression. "Medium" indicates that approximately $50 \%$ of plant tissue had stained blue, while "high" indicates that between $50-75 \%$, of plant tissue had stained blue

Expression of all three lupin derived IF3-promoter: GUS reporter gene constructs was observed in the two legume dicots (immature lupin embryos and bean callus). In addition expression was also successful in the two monocots (maize embryos and Ornithogalum callus) tissues, indicating that the $I F 3$ promoter is functional in both types of plants. From Table 1 no apparent differences in the GUS expression driven by the three promoter fragments can be seen. This was due to the high level of variability in the number of blue spots obtained between replicate bombardment experiments for each of the promotercontaining fragments. This resulted from the fact that the number of cells applied to each plate was not easy to calculate and varied from plate to plate, and from experiment to experiment. As expected, GUS activity was observed in all tissues with the positive control pDM327 (CaMV 35S promoter), whereas no GUS activity was observed for the pDM327 (negative) construct in which no promoter was present upstream from the bar-gus translational fusion gene (Table 1).

\section{Analysis of the IF3 promoter fragment for the presence of $\mathrm{Cis}$-acting regulatory elements}

In silico analyses (Berkeley Drosophila Genome Project (BDGP) Neural Network promoter prediction site (http://www.fruitfly.org/seq_tools/promoter.html) identified the most plausible core promoter sequence containing the TATA box and putative transcription start site (positions -41 to -90 and -50 , relative to the translational start site). The score value of the prediction was 0.88. Moreover, the PlantCARE database,

http://intra.psb.ugent.be:8080/PlantCARE, also identified the TATA-box of the IF3 promoter in the core promoter region at position -30 from the transcription start site. The upstream cisacting elements are of extreme importance in controlling promoter activity and, thus, regulating gene expression. In order to better understand the architecture of the IF3 promotercontaining fragment isolated from L. albus, in silico analyses were performed in order to identify putative cis-acting regulatory elements that could be important in the control of IF3 gene expression. The IF3 promoter sequence with the putative cis-elements identified is shown in Fig. S1. The summarized data in Table 2 indicate putative defense-related ciselements found in the upstream region up to $-1.8 \mathrm{~kb}$. 
Table 2: The cis-acting elements identified in the IF3 (class-III chitinase) promoter-containing fragment isolated from Lupinus albus using the PlantCARE database (Lescot et al. 2002) at:

http://intra.psb.ugent.be:8080/PlantCARE

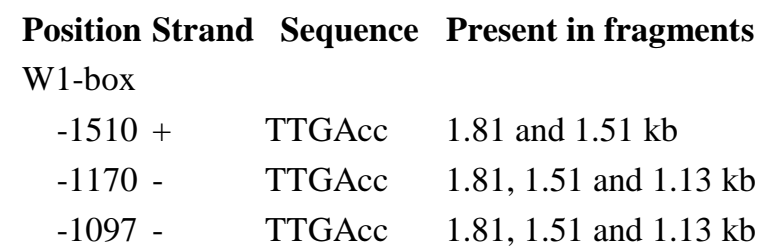

Elicitor response (ELI) - box3

$\begin{array}{ll}-1646+ & \text { AAACaatt } 1.81 \mathrm{~kb} \\ -926- & \text { AAACcaatt } 1.81,1.51 \text { and } 1.13 \mathrm{~kb} \\ -861- & \text { AAACctatt } 1.81,1.51 \text { and } 1.13 \mathrm{~kb} \\ -853- & \text { AAACcaata } 1.81,1.51 \text { and } 1.13 \mathrm{~kb} \\ -46+ & \text { AAACcaata } 1.81,1.51 \text { and } 1.13 \mathrm{~kb}\end{array}$

WUN-motif

$-1522+\quad$ cAATTtcta $1.81 \mathrm{~kb}$

$-1552+\quad$ tGATTtcta $1.81 \mathrm{~kb}$

-1727 - aCATTtcaa 1.81 and $1.51 \mathrm{~kb}$

$-934+\quad$ tAATTgcat $1.81,1.51$ and $1.13 \mathrm{~kb}$

-674 - tCATTtcat $1.81,1.51$ and $1.13 \mathrm{~kb}$

-1071 - cAATTacat $1.81,1.51$ and $1.13 \mathrm{~kb}$

$-849+\quad$ tAATTtcac $1.81,1.51$ and $1.13 \mathrm{~kb}$

$-861+\quad$ aTATTgcga $1.81,1.51$ and $1.13 \mathrm{~kb}$

$-532+\quad$ cCATTtccc $1.81,1.51$ and $1.13 \mathrm{~kb}$

$-1433+\quad$ aCATTtcaa $1.81,1.51$ and $1.13 \mathrm{~kb}$

$-431+$ tGATTtcat $1.81,1.51$ and $1.13 \mathrm{~kb}$

$-1497+\quad$ aAATTccta $1.81,1.51$ and $1.13 \mathrm{~kb}$

$-522+\quad$ cAATTacaa $1.81,1.51$ and $1.13 \mathrm{~kb}$

-495 - aAATTgcta $1.81,1.51$ and $1.13 \mathrm{~kb}$

$-1171+\quad$ cAATTtcta $1.81,1.51$ and $1.13 \mathrm{~kb}$

$-879+\quad$ tAATTtctt $1.81,1.51$ and $1.13 \mathrm{~kb}$

$-1531+\quad$ tCATTectt $1.81,1.51$ and $1.13 \mathrm{~kb}$

$-546+$ tTATTecet $1.81,1.51$ and $1.13 \mathrm{~kb}$

$88 \quad-\quad$ tGATTgcca $1.81,1.51$ and $1.13 \mathrm{~kb}$

Ethylene-responsive element (ERE)

$\begin{array}{lll}-1764+ & \text { ATTTctaa } & 1.81 \mathrm{~kb} \\ -123+ & \text { ATTTctaa } & 1.81 \mathrm{~kb} \\ -1489- & \text { ATTTcaat } & 1.81 \text { and } 1.51 \mathrm{~kb} \\ -1089- & \text { ATTTcata } & 1.81,1.51 \text { and } 1.13 \mathrm{~kb} \\ -1611- & \text { ATTTaaaa } & 1.81,1.51 \text { and } 1.13 \mathrm{~kb} \\ -497+ & \text { ATTTcaat } & 1.81,1.51 \text { and } 1.13 \mathrm{~kb} \\ -153+ & \text { ATTTctaa } & 1.81,1.51 \text { and } 1.13 \mathrm{~kb}\end{array}$

MYB binding site
$-1543+$
CGGTta $1.81 \mathrm{~kb}$
$-595+$
CGGTca
1.81 and $1.13 \mathrm{~kb}$ 
To verify the functional significance of these in silico predicted cis-elements, the inducibility of the promoter activity in response to elicitation with various treatments was investigated by means of stable transformation of the promoter-GUS constructs in the tobacco background.

\section{Transformation of tobacco with lupin IF3 promoter-GUS fusion genes, and assays for elicitor induction}

The $1.51 \mathrm{~kb}$ and $1.81 \mathrm{~kb}$ promoter-GUS fusion constructs for stable transformation of tobacco was successfully constructed, namely pBI121:Prom1.5 and pBI121:Prom1.8. The pBI121-neg colony was screened with PCR to distinguish it from native pBI121 plasmid using combinations of PCR primers (M13Rev and GUS sequencing or NOS-PolyA primers) and the expected PCR products were obtained. Restriction enzyme analysis of the other two promoter-GUS fusion constructs, using NcoI, PstI and HindIII restriction enzymes, also yielded the expected restriction patterns (data not shown). Sequencing of PCR amplified fragments of the 1.81 and $1.51 \mathrm{~kb}$ promoter-GUS fusion constructs yielded the expected sequences (data not shown).

After Agrobacterium-mediated transformation of tobacco leaf disks, a total of 45 individual T0 transgenic plants, containing the three different constructs, were clonally multiplied and analysed. Leaf disks from the individual transgenic plants were screened with PCR and GUS staining for the presence and expression of the expected promoter-GUS fusion construct and the nptII gene conferring kanamycin resistance to the transgenic tobacco (data not shown).

Representative lines, positive for PCR and GUS staining, i.e. pBI121-neg, pBI121:Prom1.5 and pBI121:Prom 1.8, were selected for studies to evaluate the elicitor-responsiveness of the two promoter fragments through activity assays of the GUS reporter gene. Figure 2 represents the average GUS activity in transgenic lines after $48 \mathrm{~h}$ treatment with different elicitors, grouped according to the elicitor treatment. pBI-neg transformed tobacco (Neg) contained no GUS activity, as expected. The different elicitors had different effects on the GUS activities. Wounding elicited much weaker responses compared to Bion, Ethepon and sodium salicylate (SA). There was no significant difference in GUS activity between the wounded and control samples, probably due to wounding-related injury when punching the leaf disks. The trend of eliciting activity of the five treatments follows a decreasing order of Bion $>$ Ethepon $>$ SA $>$ Wounding $>$ Control. 


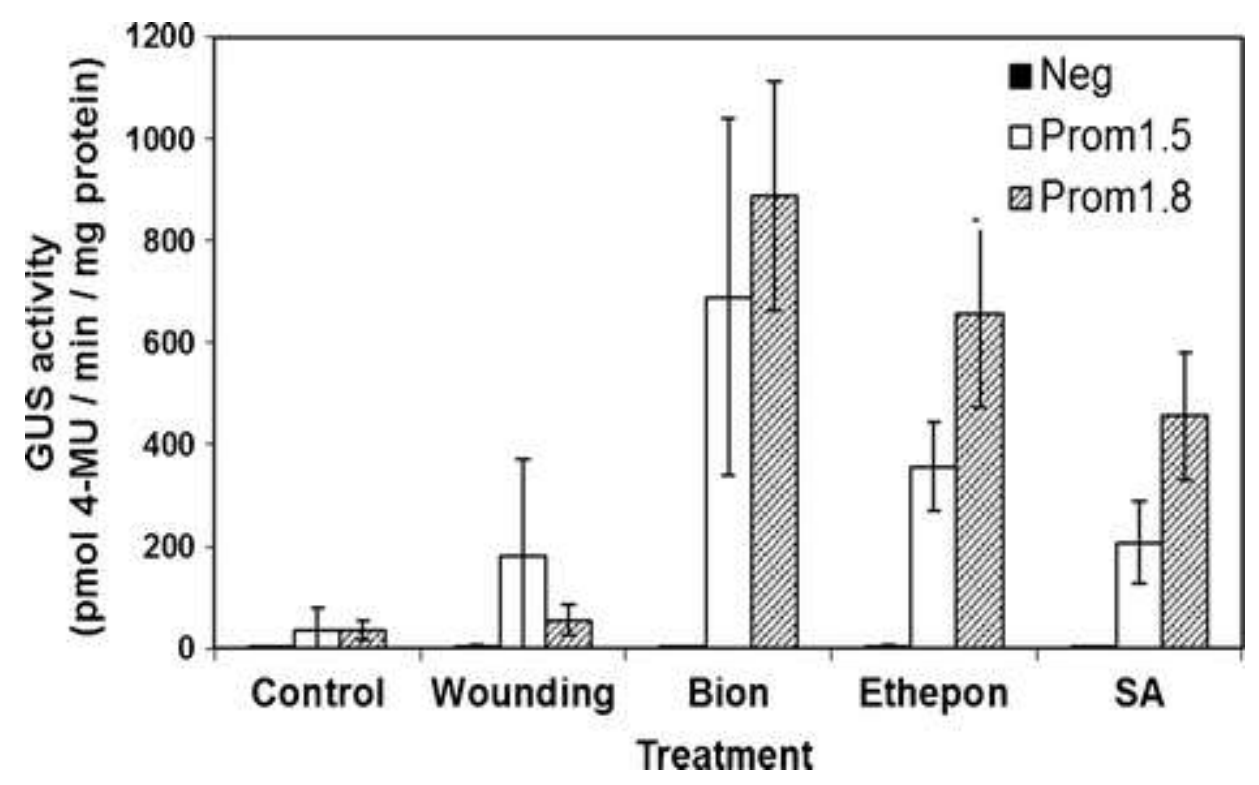

Fig. 2: GUS activity measured in leaf disks of T0 transgenic tobacco lines treated with elicitors for $48 \mathrm{~h}$. Activity is presented as pmol 4-MU released/min/mg protein. Values represent averages of triplicate biological replicates. Legend: Control (MS medium); Wounding; Bion (200 $\mu \mathrm{M})$; Ethepon (3.3 mM); SA: Salicylic acid (sodium salicylate) $(400 \mu \mathrm{M})$. Black bars: negative control, pBI121-neg; White bars: Prom1.5; Grey bars: Prom1.8. The error bars indicate the standard deviation of three biological replicates of each line

Except for wounding, all treatments (Bion, Ethepon and SA), showed statistically significant induction of GUS expression by the 1.5 and $1.8 \mathrm{~kb}$ promoter fragments at the $95 \%$ confidence level, when compared to the control untreated samples. Furthermore, the $1.8 \mathrm{~kb}$ promoter-GUS fusion plants showed higher GUS activity than the $1.5 \mathrm{~kb}$ promoter. The average GUS activity in Prom1.5 and Prom1.8 transgenic lines was also compared at an earlier time point, $24 \mathrm{~h}$ after Bion treatment (graph not shown). The induced levels of both the pBI121:Prom1.5 and pBI121:Prom1.8 transformants again showed statistically significant induction of GUS expression at the $95 \%$ confidence level, when compared to the control untreated samples. When the induced GUS activity of the Prom 1.8 fusion was compared to that of Prom 1.5, there was no statistically significant difference at $24 \mathrm{~h}$. These result, therefore, indicate that all the important elements essential for Bion inducibility are present on the shorter $(1.51 \mathrm{~kb})$ promoter fragment, but that elements found in the $300 \mathrm{bp}$ region between 1.5 and $1.8 \mathrm{~kb}$ play an additional modulating role.

\section{Discussion}

\section{Promoter identification and - architecture}

A fragment of approximately $4.2 \mathrm{~kb}$ upstream of the L. albus IF3 gene was amplified by $5^{\prime}$ gene walking. The sequence proximal to the IF3 coding sequence was compared to known sequences in the Genbank database and exhibited no significant homology. In silico analysis predicted an eukaryotic promoter site, including a TATA box, within $30 \mathrm{nt}$ from the ATG start site. In order to test for the minimal sequence needed to retain promoter activity, the $4.2 \mathrm{~kb}$ promoter-containing fragment was restricted into three smaller fragments of 1.8, 1.5 and $1.1 \mathrm{~kb}$, which were each cloned separately into the pDM327 vector upstream from the bar-gus translational fusion gene for transient Biolistic ${ }^{\mathrm{TM}}$ transformation. 
The CaMV 35S promoter used in the positive control vector pDM327 has been shown to be active after biolistic transformation of dicots (Odell et al. 1985), the legume soybean, cereals (maize, wheat)(Wang et al. 1988), and non-cereal monocots (Kamo et al. 2000). Our positive results with the CaMV 35S promoter in a range of legume and monocot tissues (Fig. 1) are consistent with these previous reports. Transient GUS expression was observed in both the monocotyledonous (maize and Ornithogalum) tissues and the dicotyledonous (bean and lupin) tissues, indicating that the IF3 promoter is functional and that the cellular environment in both types of plants is conducive to transcription of the GUS gene. This is in agreement with Regalado et al. (2000) who reported a basal level of gene expression in non-stimulated L. albus tissues. Results for Ornithogalum and bean callus tissue, as well as immature embryos tissues of maize and lupin, showed that the number of transient transformants obtained per bombardment was reasonably high, compared to the results obtained with the $35 \mathrm{~S} \mathrm{CaMV} \mathrm{promoter} \mathrm{construct} \mathrm{(pDM327).} \mathrm{In} \mathrm{addition} \mathrm{to} \mathrm{constitutive} \mathrm{activity} \mathrm{of} \mathrm{CaMV} \mathrm{35S}$ promoter observed in stably transformed plants, activity after biolistic transformation may reflect induction by wounding caused by the particle penetration of cells. This may explain partially the expression after biolistics of the IF3 promoter-constructs in our study (Fig. 1), since Regalado et al. (2000) and our study (Fig. 2) showed wounded-induced expression, although lower than biotic stressors.

It can also be assumed that all cis-acting elements needed for induction of the IF3 promoter, and, thus, transient GUS expression in all tissues tested, are present on the $1.13 \mathrm{~kb} I F 3$ promoter-containing fragment. However, no conclusions could be made as to which of the three IF3 promoter-containing fragments was the most efficient in stimulating expression of the gus reporter gene.

The TATA sequence alone is usually unable to activate transcription significantly in vivo, and additional cis-elements upstream are required to drive expression from these sites (Azhakanandam et al. 2015). The positive GUS staining suggests the presence of abundant endogenous promoter-binding factors that recognises their cis-binding sites in the isolated promoter to activate gus reporter gene expression. This prompted the investigation of the occurrence of various cis-acting elements in its architecture.

Analysis of a series of 5' deletions of the acidic class-III chitinase promoter from Arabidopsis indicated that the proximal $192 \mathrm{bp}$ upstream from the transcription start site was sufficient to establish both constitutive and inducible expression (Samac and Shah 1991). Elements further upstream were responsible for the quantitative expression of the gene and included both positive and negative regulatory elements. The study emphasised the importance of deletion studies in order to elucidate the functional organisation of a promoter fragment.

Since defense-related chitinase gene expression has been reported to be induced by various factors such as elicitors, wounding, SA and pathogen attack (Legrand et al. 1987; Ernst et al. 1992; Margis-Pinheiro et al. 1993; Graham and Sticklen 1994; Lawton et al. 1994), only the putative cis-acting elements identified in the $1.81 \mathrm{~kb} I F 3$ promoter-containing fragment that have been reported in the literature to be essential for induction by elicitors, wounding, ethylene and pathogen attack, have been annotated in Fig. S1 and summarised in Table 2.

The Box-W1 cis-acting element, present in the promoters of parsley pathogenesis related protein $1(P R-1)$ genes, has been shown to regulate the transcription of the $P R-1$ gene in response to a fungal oligopeptide elicitor (Rushton et al. 1996). The sequence (T)TGAC(C) was identified as the cis-acting element responsible for the fungal elicitor activation of the 
$P R-1$ gene, since mutations that disrupted this sequence resulted in a loss of function. Three putative Box-W1 cis-acting elements were present in the IF3 promoter-containing fragment. All three of these putative fungal elicitor responsive elements were present in the 1.81 and $1.51 \mathrm{~kb} I F 3$ promoter-containing fragments, while two of them were present in the $1.13 \mathrm{~kb}$ IF3 promoter-containing fragment.

The ELI-box3 cis-acting element has also been reported to be an elicitor responsive element (Ohl et al. 1990; Pastuglia et al. 1997). The phenylalanine ammonia-lyase (PAL) promoter from Arabidopsis contains two ELI-box3 regulatory elements reported to contain elicitor inducible activity (Ohl et al. 1990), and these elements have also been identified in a PAL gene from parsley (Lois et al. 1989). The ELI-box3 element is also present in the promoter of an S gene family receptor-like kinase (SRK) in Brassicca oleracea (Pastuglia et al. 1997). Five putative ELI-box 3 cis-acting elements were present in the IF3 promoter-containing fragment. All five of these putative fungal elicitor responsive elements were present in the $1.81 \mathrm{~kb}$ IF3 promoter-containing fragment, while four of them were present in the 1.51 and $1.13 \mathrm{~kb} I F 3$ promoter-containing fragments.

The WUN-motif has been identified as a wound-inducible cis-acting element (Matton et al. 1993; Pastuglia et al. 1997; Kaothien et al. 2000). The sth-2 promoter of the sth-2 pathogenesis-related gene in potato was reported to contain the WUN-motif (Matton et al. 1993) that has been reported to regulate the wound-inducible activity of the wun 1 and wun 2 genes from potato (Siebertz et al. 1989; Stanford et al. 1989). The WUN-motif was also present in the promoter of a srk gene in Brassicca oleracea (Pastuglia et al. 1997). Nineteen putative WUN-motif cis-acting elements were present in the IF3 promoter-containing fragment. All 19 of these putative wound responsive elements were present in the $1.81 \mathrm{~kb} I F 3$ promoter-containing fragment, 17 of them in the $1.51 \mathrm{~kb} I F 3$ promoter-containing fragment and 16 of them in the $1.13 \mathrm{~kb} I F 3$ promoter-containing fragments.

The expression of several plant chitinases have been shown to be induced by ethylene (Broglie et al. 1986; Memelink et al. 1990). Ethylene levels usually increase in response to stresses such as wounding and pathogen attack (Samac and Shah 1991). The ERE cis-acting element has been identified as an ethylene-responsive element (Itzhaki et al. 1994). Seven putative ERE cis-acting elements were present in the IF3 promoter-containing fragment. All seven of these putative wound responsive elements were present in the $1.81 \mathrm{~kb} I F 3$ promotercontaining fragment, while five of them were present in the $1.51 \mathrm{~kb}$ IF3 promoter-containing fragment, and four of them in the $1.13 \mathrm{~kb} I F 3$ promoter-containing fragment.

Wounding occurred during the Biolistic ${ }^{\mathrm{TM}}$ transformation of plant tissues in which the IF3 promoter-containing fragments were tested for promoter activity, using transient GUS expression as indicator. Thus, it is hypothesised that due to the inducibility of the IF3 promoter, that gus gene expression was activated as a result of the putative wound-inducible (WUN-motif) and ethylene responsive element (ERE) cis-acting elements. These data also show that most of these wound-inducible regulatory elements are present in the $1.13 \mathrm{~kb}$ IF3 promoter-containing fragment. This could explain why this fragment was just as efficient in the activation of gus reporter gene, resulting in levels of transient GUS expression similar to that obtained with the 1.51 and $1.81 \mathrm{~kb} I F 3$ promoter-containing fragments cloned upstream from the bar-gus translational fusion gene in pDM327.

Included in the elements listed in Table 2, are two putative Myb transcription factor binding site regulatory cis-acting elements, found to be present in the 1.81 and one in the $1.13 \mathrm{~kb}$ IF3 
promoter-containing fragments respectively. Myb factors regulate the transcription of several plant genes in response to various environmental factors, including elicitors and wounding (Jin and Martin 2000; Sugimoto et al. 2000). The Myb sites are often located upstream from pathogen-inducible genes (Rushton and Somssich 1998).

The CAAT box element (consensus GCCCAATCT) plays an important role in the determination of promoter efficiency and several were also identified within the IF3 promoter-containing fragments (data not shown). However, since these are not associated with inducibility of defense genes they have not been indicated in the analysis.

These in silico analyses indicate that most of the putative fungal elicitor activated cis-acting elements are present in the $1.13 \mathrm{~kb} I F 3$ promoter-containing fragment and supports the hypothesis that all regulatory elements needed for the activation of the IF3 gene promoter are located within the first $1.13 \mathrm{~kb}$ fragment upstream from the initiation codon of the IF3 gene.

\section{Promoter inducibility}

The applicability of promoter-reporter gene fusions has been shown previously in transgenic tobacco transformed with a chimeric $1.7 \mathrm{~kb}$ fragment containing the bean chitinase $5 B$ gene promoter and the gus gene. This promoter was transiently activated after fungal attack and the greatest induction of GUS expression was observed in and around the site of fungal infection (Roby et al. 1990). Following fungal infection, the increase in GUS activity reached a maximun at $48 \mathrm{~h}$ post infection and paralleled the increase in endogenous tobacco chitinase activity.

Here the GUS fusion gene concept was used to investigate the responsiveness of the IF3 promotor deletions to chemical elicitation with Bion (acibenzolar- $S$-methyl benzo- $(1,2,3)$ thiadiazole-7-carbothioic acid $S$-methyl ester or BTH), signal molecules (SA and ethylene) and wounding. Exogenous application of chemicals such as SA, Bion and INA (2,6dichloroisonicotinic acid) has been shown to activate the plant's natural immune responses (Ward et al. 1991). Bion is a water dispersible chemical used during plant cultivation, which elicits systemic acquired resistance (SAR) and stimulates the natural defense mechanisms of various plants against plant diseases to provide protection against damage caused by undesired microbes. Bion is a functional analog of SA because it induces the expression of known SA-responsive genes, but it acts independently of SA perception and biosynthesis (Kessmann et al. 1993; Friedrich et al. 1996), suggesting that it interacts with biological targets operating downstream from these steps.

To verify the functional significance of these in silico predicted cis-elements, the inducibility of the promoter activity in response to elicitation with various treatments was investigated at $24 \mathrm{~h}$ and $48 \mathrm{~h}$ post teatment by means of stable transformation of the promoter-GUS constructs in the heterologous tobacco background (Fig. 2). Promoter activation by, and the consequent inducibility of the GUS reporter gene, confirm that the IF3 promoter fragment isolated from lupin is functional in planta and that the promoter is inducible to different extents by different elicitors. Notwithstanding biological variability, collection of quantitative promoter expression data indicated that both the $1.51 \mathrm{~kb}$ and $1.81 \mathrm{~kb}$ fragments of the promoter are highly inducible by Bion, but also, to a lower extent, responsive towards SA, ethylene and wounding. This might be an indication that both $5^{\prime}$ distal and proximal cisacting regulator elements are required for full functionality of the promoter (Zheng et al. 1993). 


\section{Conclusion}

In summary, the L. albus IF3 promoter contains all the properties to allow its associated gene and the encoded class III chitinase to function as an inducible pathogenesis-related protein in the defense arsenal of lupin. As such, the IF3 promoter would also be suitable to drive expression of genes that could potentially be used to enhance fungal resistance of transgenic plants. Moreover, the IF3 promoter-containing fragment:gus chimeric genes produced in this study are suitable tools to study the cellular and molecular mechanisms of the activation of the host defense system in lupin as well as other legume crops during pathogen attack.

\section{Acknowledgments}

The financial assistance of the South African Agricultural Research Council (ARC) and the Protein Research Trust (PRT) towards this research is hereby acknowledged. Opinions expressed and conclusions arrived at, are those of the authors and are not necessarily to be attributed to ARC or PRT. We thank L. Morey for assistance with the statistical analysis.

\section{Compliance with ethical standards}

\section{Conflict of interest}

The authors declare no competing interests.

\section{References}

Adhikari, K. N., Buirchell, B. J., Thomas, G. J., Sweetingha, M. W., \& Yang, H. (2009). Identification of anthracnose resistance in Lupinus albus $\mathrm{L}$. and its transfer from landraces to modern cultivars. Crop and Pasture Science, 60, 472-479. Adhikari, K. N., Thomas, G., Diepeveen, D., \& Trethowan, R. (2013). Overcoming the barriers of combining early flowering and anthracnose resistance in white lupin (Lupinus albus L.) for the Northern agricultural region of Western Australia. Crop and Pasture Science, 64, 914-921.

Azhakanandam, K., Silverstone, A., Daniell, H., \& Davey, M. R. (Eds.) (2015). Recent advancements in gene expression and enabling technologies in crop plants (pp. 1-422). New York: Springer Verlag publishers.

Bradford, M. M. (1976). A rapid and sensitive method for the quantitation of microgram quantities of protein utilizing the principle of protein-dye binding. Analytical Biochemistry, 72, 248-254.

Broekaert, W. F., Van Parijs, J., Allen, A. K., \& Peumans, W. J. (1988). Comparison of some molecular, enzymatic and antifungal properties of chitinases from thorn-apple, tobacco and wheat. Physiological and Molecular Plant Pathology, 33, 319-331.

Broglie, K. E., Gaynor, J. J., \& Broglie, R. M. (1986). Ethylene-regulated gene expression: molecular cloning of the genes encoding an endochitinase from Phaseolus vulgaris. Proceedings of the National Academy of Sciences of the United States of America, 83, 6820-6824.

Broglie, K., Chet, I., Holliday, M., Cressman, R., Biddle, P., Knowlton, S., et al. (1991). Transgenic plants with enhanced resistance to the fungal pathogen Rhizoctonia solani. Science, 254, 1194-1197. 
Bustos, M. M., Guiltinan, M. J., Jordano, J. H., Begum, D., Kalkan, F. A., \& Hall, T. C. (1989). Regulation of $\beta$-glucuronidase expression in transgenic tobacco plants by an $\mathrm{A} / \mathrm{T}$ rich, cis-acting sequence found upstream of french bean $\beta$-phaseolin gene. The Plant Cell, 1, 839-853.

Chang, W. C., Lee, T. Y., Huang, H. D., Huang, H. Y., \& Pan, R. L. (2008). PlantPAN: plant promoter analysis navigator, for identifying combinatorial cis-regulatory elements with distance constraint in plant gene groups. BMC Genomics, 9, 561.

Collinge, D. B., Kragh, K. M., Mikkelsen, I. D., Nieler, K. K., Rasmussen, U., \& Vad, K. (1993). Plant chitinases. Plant Journal, 3, 31-40.

Cornejo, M. J., Luth, D., Blankenship, K. M., Anderson, O. D., \& Blechl, A. E. (1993). Activity of a maize ubiquitin promoter in transgenic rice. Plant Molecular Biology, 23, 567-581.

De Villiers, S. M., Kamo, K., Thomson, J. A., Bornman, C. H., \& Berger, D. K. (2001). Biolistic transformation of chincherinchee (Ornithogalum) and regeneration of transgenic plants. Physiologia Plantarum, 109, 450-455.

Ernst, D., Schraudner, M., Langebartels, C., \& Sandermann, H. (1992). Ozone induced changes in mRNA levels of $\beta$-1,3-glucanase, chitinase and pathogenesis-related protein $1 \mathrm{~b}$ in tobacco plants. Plant Molecular Biology, 20, 673-682.

Friedrich, L., Lawton, K., Reuss, W., Masner, P., Specker, N., Gut Rella, M., et al. (1996). A benzothiadiazole induces systemic acquired resistance in tobacco. Plant Journal, 10, 61-70. GenStat (2011) 64-bit Release 14.1 (PC/Windows 7) Copyright 2011, VSN International Ltd.

Graham, L. S., \& Sticklen, M. B. (1994). Plant chitinases. Canadian Journal of Botany, 72, 10571083.

Grover, A. (2012). Plant chitinases: genetic diversity and physiological roles. Critical Reviews in Plant Sciences, 31, 57-73.

Gurr, S. J., \& Rushton, P. J. (2005). Engineering plants with increased disease resistance: how are we going to express it? Trends in Biotechnology, 23, 283-290.

Henrissat, B., \& Bairoch, A. (1993). New families in the classification of glycosyl hydrolases based on amino acid sequence similarities. Biochemical Journal, 293, 781-788.

Higo, K., Ugawa, Y., Iwamoto, M., \& Korenaga, T. (1999). Plant cis-acting regulatory DNA elements (PLACE) database: 1999. Nucleic Acids Research, 27, 297-300.

Itzhaki, H., Maxson, J. M., \& Woodson, W. R. (1994). N ethylene-responsive enhancer element is involved in the senescence-related expression of the carnation glutathione-S-transferase (GST1) gene. Proceedings of the National Academy of Sciences of the United States of America, 91, 8925-8929.

Jach, G., Gornhardt, B., Mundy, J., Logemann, J., Pinsdorf, E., Leah, R., et al. (1995). Enhanced quantitative resistance against fungal disease by combinatorial expression of different barley antifungal proteins in transgenic tobacco. Plant Journal, 8, 97-109.

Jefferson, R. A., Kavanagh, T. A., \& Bevan, M. W. (1987). GUS fusions: $\beta$-glucuronidase as a sensitive and versatile gene fusion marker in higher plants. EMBO Journal, 6, 3901-3907. 
Jin, H., \& Martin, C. (2000). Multifunctionality and diversity within the plant MYB-gene family. Nucleic Acids Research, 28, 2004-2011.

Kamo, K., McElroy, D., \& Chamberlain, D. (2000). Transforming embryonic cell lines of Gladiolus with either a bar-uidA fusion gene or cobombardment. In Vitro Cellular and Developmental Plant Biology, 36, 182-187.

Kaothien, P., Shimokawatoko, Y., Kawaoka, A., Yoshida, K., \& Shinmyo, A. (2000). A cis-element containing PAL-box functions in the expression of the wound-inducible peroxidase gene of horseradish. Pant Cell Reports, 19, 558-562.

Kessmann, H., Staub, T., Hofmann, C., Ahl Goy, P., Ward, E., Uknes, S., et al. (1993). Induced disease resistance by isonicotinic acid derivatives. Japan Journal of Pesticide Science, 10, 29-37.

Koch, S. H., Ghebremariam, D. S., \& Swart, W. J. (2002). Susceptibility of lupin cultivars to south African isolates of Colletotrichum gloeosporioides associated with lupin anthracnose. African Plant Protection, 8, 51-56.

Lawton, K. A., Beck, J., Potter, S., Ward, E., \& Ryals, J. (1994). Regulation of cucumber class III chitinase gene expression. Molecular Plant-Microbe Interactions, 7, 335-341.

Legrand, M., Kauffmann, S., Geoffroy, P., \& Fritig, B. (1987). Biological function of pathogenesisrelated proteins: four tobacco pathogenesis-related proteins are chitinases. Proceedings of the National Academy of Sciences of the United States of America, 84, 6750-6754.

Lescot, M., Dehais, P., Thijs, G., Marchal, K., Moreau, Y., Van de Peer, Y., et al. (2002). PlantCARE, a database of plant cis-acting regulatory elements and a portal to tools for the in silico analysis of promoter sequences. Nucleic Acids Research, 30, 325-327.

Lois, R., Dietrich, A., Hahlbrock, K., \& Schulz, W. (1989). A phenylalanine ammonia-lyase gene from parsley: structure, regulation, and identification of elicitor and light responsive cis-acting elements. EMBO Journal, 8, 1641-1648.

Lotter, H. C., \& Berger, D. K. (2005). Anthracnose of lupins in South Africa in caused by Colletotrichum lupini var. setosum. Australasian Plant Pathology, 34, 385-392.

Margis-Pinheiro, M., Martin, C., Didierjean, L., \& Burkard, G. (1993). Differential expression of bean chitinase genes by virus infection, chemical treatment and UV irradiation. Plant Molecular Biology, 22, 659-668.

Matton, D. P., Prescott, G., Bertrand, C., Camirand, A., \& Brisson, N. (1993). Identification of cisacting elements involved in the regulation of the pathogenesis-related gene STH-2 in potato. Plant Molecular Biology, 22, 279-291.

Mauch, F., Mauch-Mani, B., \& Boller, T. (1988). Antifungal hydrolases in pea tissue. II. Inhibition of funga1 growth by combinations of chitinase and P-1,3-glucanase. Plant Physiology, 88, 936-942.

Memelink, J., Linthorst, H. J. M., Schilperpoort, R. A., \& Hoge, J. H. C. (1990). Tobacco genes encoding acidic and basic isoforms of pathogenesis-related proteins display different expression patterns. Plant Molecular Biology, 14, 119-126.

Murray, M. G., \& Thompson, W. F. (1980). Rapid isolation of high molecular weight plant DNA. Nucleic Acids Research, 8, 4321-4325. 
Neuhaus, J.-M. (1999). Plant chitinases (PR-3, PR-4, PR-8, PR-11). In S. K. Datta \& S.

Muthukrishnan (Eds.), Pathogenesis-related proteins in plants (pp. 77-105). Boca Raton, FL: CRC

Press.

New, S.-A., Piater, L. A., \& Dubery, I. A. (2015). In silico characterization and expression analysis of selected Arabidopsis receptor-like kinase genes responsive to different MAMP inducers. Biologia Plantarum, 59, 18-28.

Nirenberg, H. I., Feiler, U., \& Hagedorn, G. (2002). Description of Colletotrichum lupini comb. nov. in modern terms. Mycologia, 94, 307-320.

Odell, J. T., Nagy, F., \& Chua, N.-H. (1985). Identification of DNA sequences required for activity of the cauliflower mosaic virus $35 \mathrm{~S}$ promoter. Nature, $313,810-812$.

Ohl, S., Hedrick, S. A., Chory, J., \& Lamb, C. (1990). Functional properties of a phenylalanine ammonia-lyase promoter from Arabidopsis. The Plant Cell, 2, 837-848.

Pastuglia, M., Roby, D., Dumas, C., \& Cock, J. M. (1997). Rapid induction by wounding and bacterial infection of an S gene family receptor-like kinase gene in Brassica oleracea. The Plant Cell, $9,49-60$.

Porto, M. S., Pinheiro, M. P. N., Batista, V. G. L., dos Santos, R. C., Filho, P. A. M., \& de Lima, L. M. (2014). Plant promoters: an approach of structure and function. Molecular Biotechnology, 56, 3849.

Regalado, A. P., Pinheiro, C., Vidal, S., Chaves, I., Ricardo, C. P. P., \& Rodrigues-Pousada, C. (2000). The Lupinus albus class-III chitinase gene, $I F 3$, is constitutively expressed in vegetative organs and developing seeds. Planta, 210, 543-550.

Roby, D., Broglie, K., Cressman, R., Biddle, P., Chet, I., \& Broglie, R. (1990). Activation of a bean chitinase promoter in transgenic tobacco plants by phytopathogenic fungi. Plant Cell, 2, 999-1008.

Rushton, P. J., \& Somssich, I. E. (1998). Transcriptional control of plant genes responsive to pathogens. Current Opinion in Plant Biology, 1, 311-315.

Rushton, P. J., Torres, J. T., Parniske, M., Wernert, P., Hahlbrock, K., \& Somssich, I. E. (1996). Interaction of elicitor-induced DNA-binding proteins with elicitor response elements in the promoters of parsley PR1 genes. EMBO Journal, 15, 5690-5700.

Samac, D. A., \& Shah, D. M. (1991). Developmental and pathogen-induced activation of the Arabidopsis acidic chitinase promoter. The Plant Cell, 3, 1063-1072.

Sambrook, J., Fritsch, E. F., \& Maniatis, T. (1989). Molecular cloning. A laboratory manual (2nd ed.). Cold Spring Harbor, NY, USA: Cold Spring Harbor Laboratory Press.

Siebertz, B., Logemann, J., Willmitzer, L., \& Schell, J. (1989). Cis-analysis of the wound-inducible promoter wunl in transgenic tobacco plants and histochemical localization of its expression. The Plant Cell, 1, 961-968.

Stanford, A. C., Bevan, M. H., \& Northcote, D. H. (1989). Differential expression within a family of novel wound-induced genes in potato. Molecular and General Genetics, 215, 200-208. 
Sugimoto, K., Takeda, S., \& Hirochika, H. (2000). MYB-related transcription factor NtMYB2 induced by wounding and elicitors is a regulator of the tobacco retrotransposon Tto1 and defenserelated genes. The Plant Cell, 12, 2511-2528.

Thomasset, B., Menard, M., Boetti, H., Denmat, L. A., Inze, D., \& Thomas, D. (1996). $\beta$ Glucuronidase activity in transgenic and non-transgenic tobacco cells: specific elimination of plant inhibitors and minimization of endogenous GUS background. Plant Science, 113, 209-219.

Verberg, J. G., \& Huynh, Q. K. (1991). Purification and characterization of an antifungal chitinase from Arabidopsis thaliana. Plant Physiology, 95, 450-455.

Wang, Y.-C., Klein, T. M., Fromm, M., Cao, J., Sanford, J. C., \& Wu, R. (1988). Transient expression of foreign genes in rice, wheat and soybean cells following particle bombardment. Plant Molecular Biology, 11, 433-439.

Ward, E. R., Uknes, S. J., Williams, S. C., Dincher, S. S., Wiederhold, D. L., Alexander, D. C., et al. (1991). Coordinate gene activity in response to agents that induce systemic acquired resistance. Plant Cell, 3, 1085-1094.

Yeboah, N. A., Arahira, M., Nong, V. H., Zhang, D., Kadokura, K., Watanabe, A., et al. (1998). A class III acidic endochitinase is specifically expressed in the developing seeds of soybean (Glycine max L. Merr.). Plant Molecular Biology, 36, 407-415.

Zheng, Z., Kawagoe, Y., Xiao, S., Li, Z., Okita, T., Hau, T. L., et al. (1993). 5' distal and proximal cis-acting regulator elements are required for developmental control of a rice seed storage protein glutelin gene. Plant Journal, 4, 357-366. 


\section{Supplementary material}

$-1800$

$-1780$

$-1760$

$-1740$

$-1720$ CCATGGACAAGgGGTTCAGATGATGACAGTACTGGGAGdCAAATATGTGGCTCAATTTdTAAGGCACTGTTTCGGGATGATGATCTTTAATGTTAGTAAG GGTACCTGTTCCCCAAGTCTACTACTGTCATGACCCTCGGTTTATACACCGAGTTAAAGATTCCGTGACAAAGCCCTACTACTAGAAATTACAATCATTC

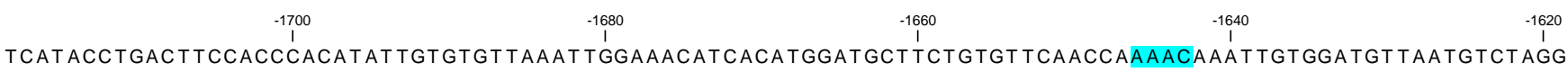
AGTATGGACTGAAGGTGGGTGTATAACACACAAT T TAACCTTTGTAGTGTACCTACGAAGACACAAGT TGGTTTTGTTTAACACCTACAATTACAGATCC

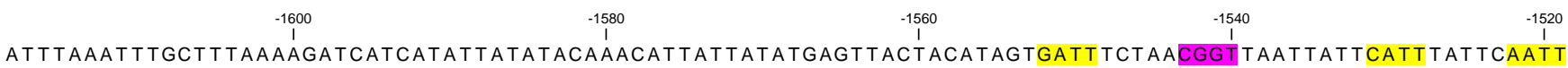
TAAATTTAAACGAAATTTTCTAGTAGTATAATATATGTTTGTAATAATATACTCAATGATGTATCACTAAAGATTGCCAATTAATAAGTAAATAAGTTAA

$\begin{array}{llll}-1500 & -1480 & -1460 & -1440\end{array}$

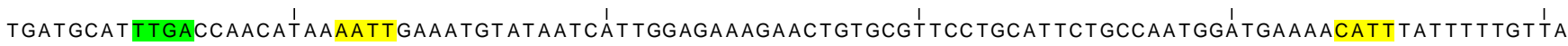
ACTACGTAAACTGGTTGTATTTTAACTTTACATATTAGTAACCTCTTTCT TGACACGCAAGGACGTAAGACGGTTACCTACTTTTGTAAATAAAAACAAT

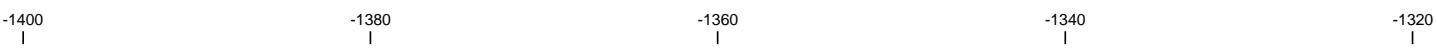

CTATGTTGCAAAAGGTGTGTATATATTCATAGAATCATTGTCAGAGGCAGTAGGGTTTCTGTTCCAGACTTGTATCACTGCTAACTTCATGAATTTACAA GATACAACGTTTTCCACACATATATAAGTATCTTAGTAACAGTCTCCGTCATCCCAAAGACAAGGTCTGAACATAGTGACGATTGAAGTACTTAAATGT T $\begin{array}{ccc}-1300 & -1280 & -1260\end{array}$ TT TCGTTGAATCAAATAGGTTAAGACAAGGTCTGAAAGGAATTAACCTACCAAAGGGAAATCCGAAGTGGTTTGAACCTTTTGTTCGAAGGACGATACAG

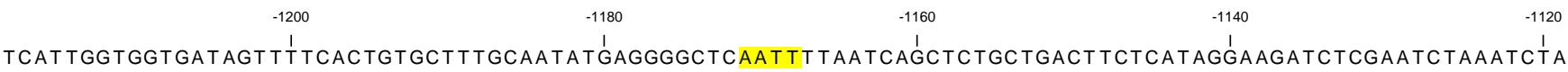
AGTAACCACCACTATCAAAAGTGACACGAAACGT TATACTCCCCGAGT TAAAAT TAGTCGAGACGACTGAAGAGTATCCT TCTAGAGCT TAGATT TAGAT

\begin{tabular}{|c|c|c|}
\hline-1100 & -1080 & -1060 \\
\hline
\end{tabular}
ATTGCATGCCT TGT TGGGTCAATATGAAATGAAAAAAAAAATGTAATTGAAAAATATGTTGGGTTTGTTGTATGGGCCTATAGATCAAGCTCACTTAGAC TAACGTACGGAACAACCCAGTTATACTT TACT TTTTTTTTTACATTAACT TT TATACAACCCAAACAACATACCCGGATATCTAGTTCGAGTGAATCTG

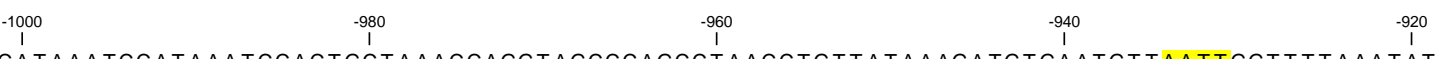
ATTTAGCAGATCCATACCA I AAATCCATAAATCCACTGCTAAACCAGGTAGCCCAGCCTAACCTGTTATAAAGATGTGAATGTTAATTGGTTTTAAATAT TAAATCGTCTAGGTATGGTATTTAGGTATTTAGGTGACGATTTGGTCCATCGGGTCGGATTGGACAATATTTCTACACTTACAATTAACCAAAATTTATA

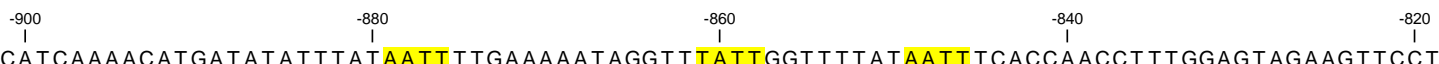
CCAGGATGTAAAATTTACATCAAAACATGATATATTTATAATTTTGAAAAATAGGTTTATTGGTTTTATAATTTCACCAACCTTTGGAGTAGAAGTTCCT GGTCCTACATTTTAAATGTAGTTTTGTACTATATAAATATTAAAACTTTTTATCCAAATAACCAAAATATTAAAGTGGTTGGAAACCTCATCTTCAAGGA $\begin{array}{ccccc}-800 & -780 & -760 & -740 & -720 \\ \text { I } & 1 & 1 & 1 & 1\end{array}$ TCACCCTACAGCATCCTGATGATAATAAACCTGCAAAT TAAATTAATTCAGTCTTCTAAAATTATGGTCTGGTTACTTTAAACTCGTTAAAGGAAAAACA AGTGGGATGTCGTAGGACTACTATTATTTGGACGTTTAATTTAATTAAGTCAGAAGATTTTAATACCAGACCAATGAAATTTGAGCAATTTCCTTTTTGT

$-700$ $-680$ $-660$ AAAATCT TAATTCACTAAATATTGCGAAAAAAATGTATACAAATGAAGTAACTGAAAGAAAACGTAGTTGAATTGGTCTAGCTCTGCTATGATGGATGAA TTTTAGAATTAAGTGATTTATAACGCTTTTTTTACATATGTTTACT TCATTGACTTTCTTTTGCATCAACTTAACCAGATCGAGACGATACTACCTACTT

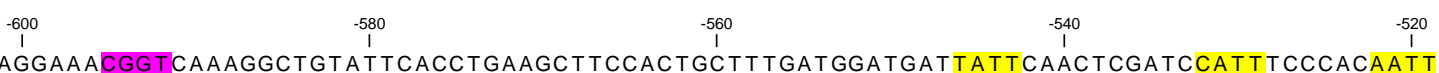
AGGATGGGGCCAAACAGAGGAAACGGTCAAAGGCTGTATTCACCTGAAGCTTCCACTGCTTTGATGGATGATTATTCAACTCGATCCATTTCCCACAATT TCCTACCCCGGTTTGTCTCCTTTGCCAGTTTCCGACATAAGTGGACTTCGAAGGTGACGAAACTACCTACTAATAAGT TGAGCTAGGTAAAGGGTGT TAA

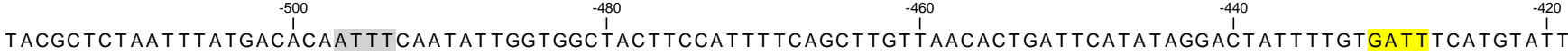
ATGCGAGATTAAATACTGTGTTAAAGTTATAACCACCGATGAAGGTAAAAGTCGAACAATTGTGACTAAGTATATCCTGATAAAACACTAAAGTACATAA 


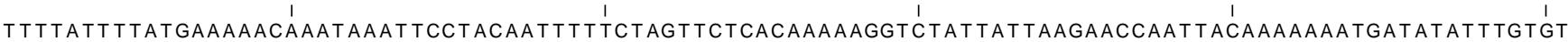
AAAATAAAATACTTTTTGTTTATTTAAGgATGTTAAAAAGATCAAGAGTGTTTTTCCAGATAATAATTCTTGGTTAATGTTTTTTTACTATATAAACACA

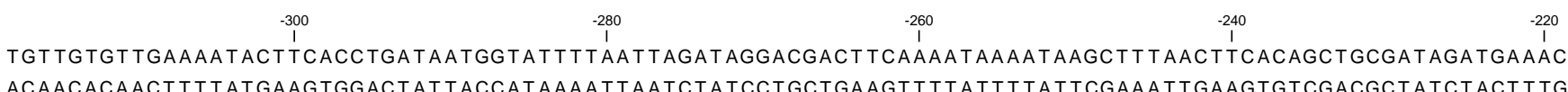
ACAACACAACTTTTATGAAGTGGACTATTACCATAAAATTAATCTATCCTGCTGAAGTTTTATTTTATTCGAAATTGAAGTGTCGACGCTATCTACTTTG

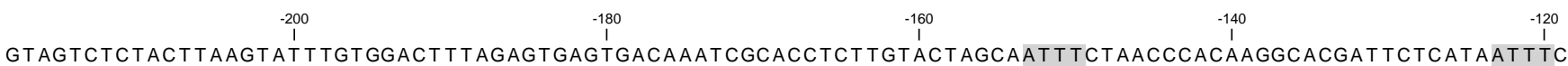
CATCAGAGATGAATTCATAAACACCTGAAATCTCACTCACTGT T TAGCGTGGAGAACATGATCGTTAAAGATTGGGTGTTCCGTGCTAAGAGTATTAAAG

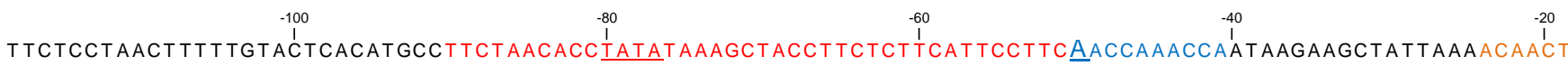
AAGAGGAT TGAAAACATGAGTGTACGGAAGATTGTGGATATATTTCGATGGAAGAGAAGTAAGGAAGTTGGTTTGGTTATTCTTCGATAATTTTGTTGA

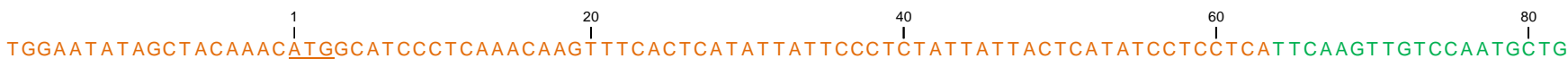
ACCTTATATCGATGTTTGTACCGTAGgGAGTTTGT TCAAAGTGAGTATAATAAGgGAGATAATAATGAGTATAGGAGGAGTAAGT TCAACAGGT TACGAC

100

CTGGCAATCACTAGTGAATTC

GACCGTTAGTGATCACTTAAG

Figure S1. The complete sequence of the $1.818 \mathrm{~kb}$ class-III chitinase (if3) promoter-containing fragment isolated from Lupinus albus (corresponding to the 3' end of the $4.2 \mathrm{~kb}$ sequence deposited on Genbank Acc\# KP981368).

In silico analyses (Berkeley Drosophila Genome Project (BDGP) Neural Network promoter prediction site http://www.fruitfly.org/seq_tools/promoter.html) identified the most likely core promoter sequence within the fragment (red text, -41 to $-90 \mathrm{nt}$ ) with $\underline{\text { TATA }}$ box underlined) and annotated the transcription start site (ㅁ) and translation starts site (ATG). The promoter prediction score was 0.89 . Also indicated are the L. albus if3 gene sequence (brown text) and the primer designed for Genome Walking (green text). Putative cis-elements identified using PlantCARE (http://intra.psb.ugent.be:8080/PlantCARE; Lescot et al., 2002) are indicated with the following colour codes:

\section{W1-box}

Elicitor response (ELI) - box3

WUN-motif

Ethylene-responsive element (ERE

MYB binding site 


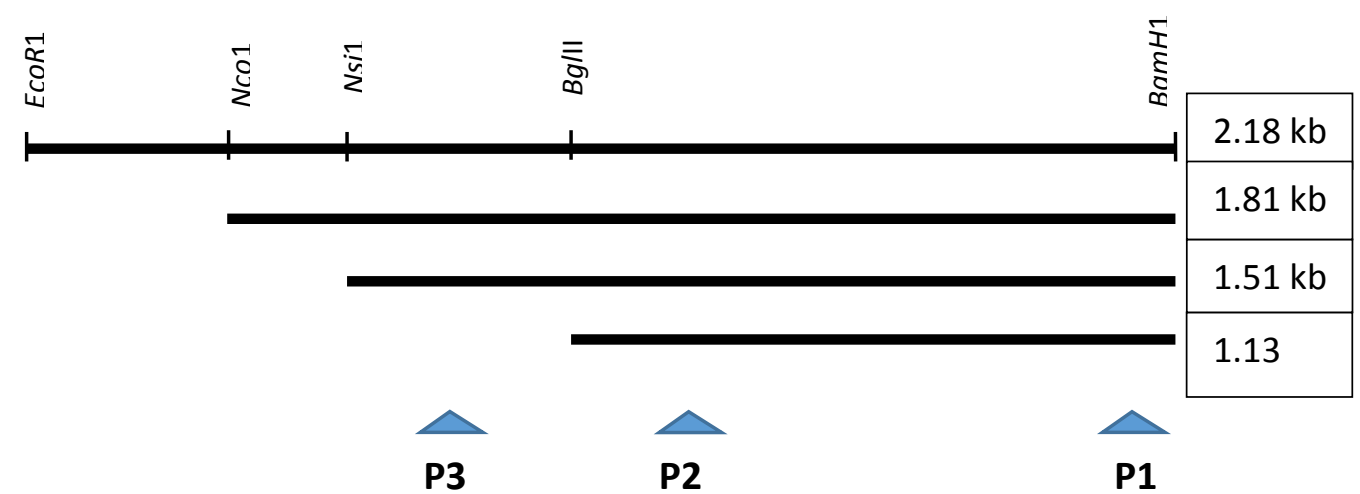

Figure S2 A graphic representation of the 3' section of the $4.2 \mathrm{~kb}$ class-III chitinase (IF3) promoter-containing fragment isolated from Lupinus albus. Following promoter prediction analysis, the $2.18 \mathrm{~kb}$ fragment obtained from the pGEM:2.2Promoter was cut with restriction enzymes to yield $1.81 \mathrm{~kb}$ and $1.51 \mathrm{~kb}$ fragments (each containing three predicted core promoter elements: P1, P2 and P3), and a $1.13 \mathrm{~kb}$ fragment (containing 2 predicted core promoter sequences: P1 and P2). The score values of P1, P2 and P3 were $0.88,0.81$ and 0.81 respectively.

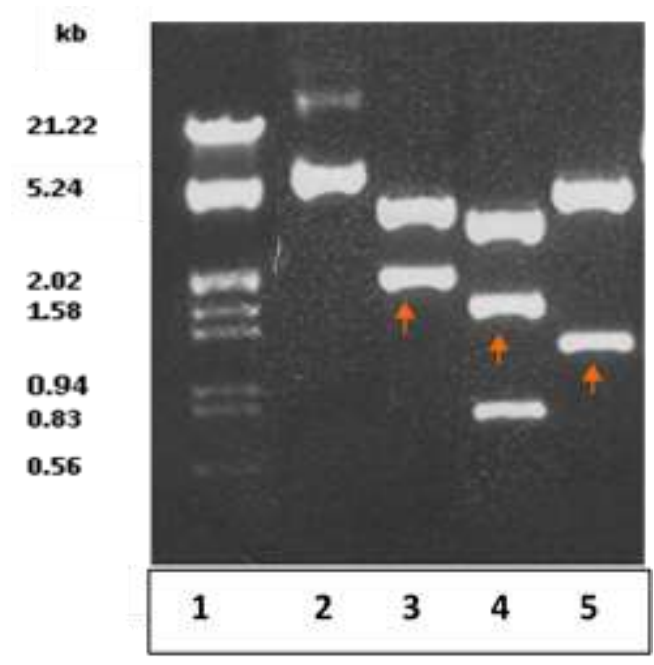

Figure S3 Restriction enzyme digests of the pGEM:2.2Promoter for the creation of constructs corresponding to $1.81,1.51$ and $1.13 \mathrm{~kb}$ class-III chitinase (IF3) promoter-containing fragments, respectively. Lane 1: Molecular Weight Marker III (Roche); Lane 2: uncut pGEM:2.2Promoter clone; Lane 3: NcoI/BamHI digest; Lane 4: Nsi//BamHI digest; Lane 5: BglII/BamHI digest. The arrows indicate the expected 1.81, 1.51 and $1.13 \mathrm{~kb} I F 3$ promoter-containing fragments. 

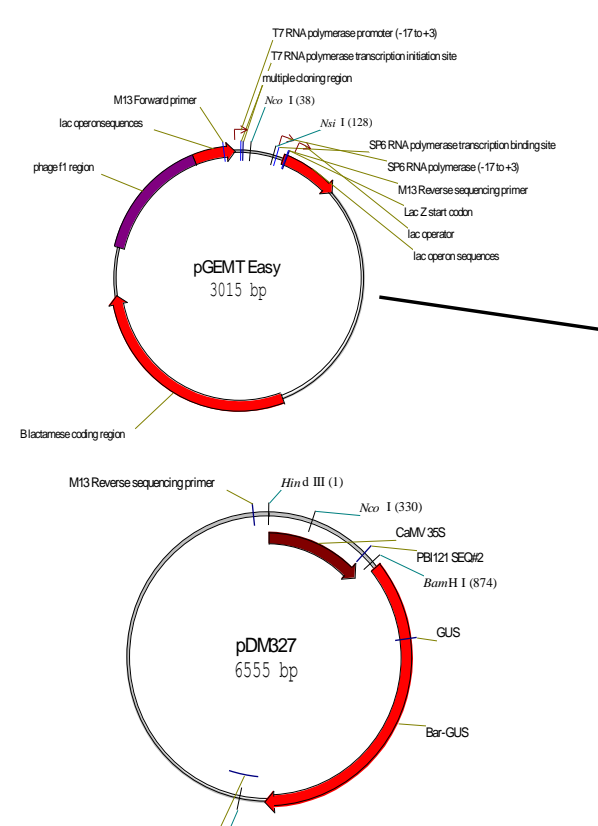

NOS

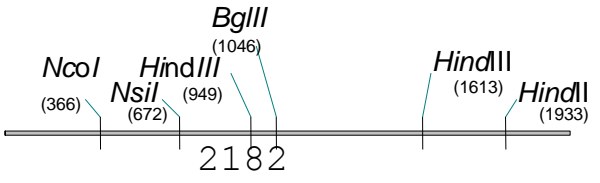

Class-III chitinase promoter (PCR amplified from pGEM:4.2Promoter

ligation and transformation

\section{pDM327:HindII/BamH pGEM:2.2Promoter: $\mathrm{Bg} / \mathrm{ll} / \mathrm{BamH}$}

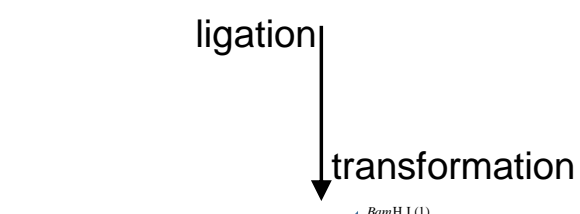

Note: After restriction with either HindlII, Ncol, Nsil or Bg/ll the restricted DNA was subjected to a Klenow (DNA Polymerase I Large Fragment) polymerase step to produce blunt-ended fragments prior to the restriction with $\mathrm{BamH}$
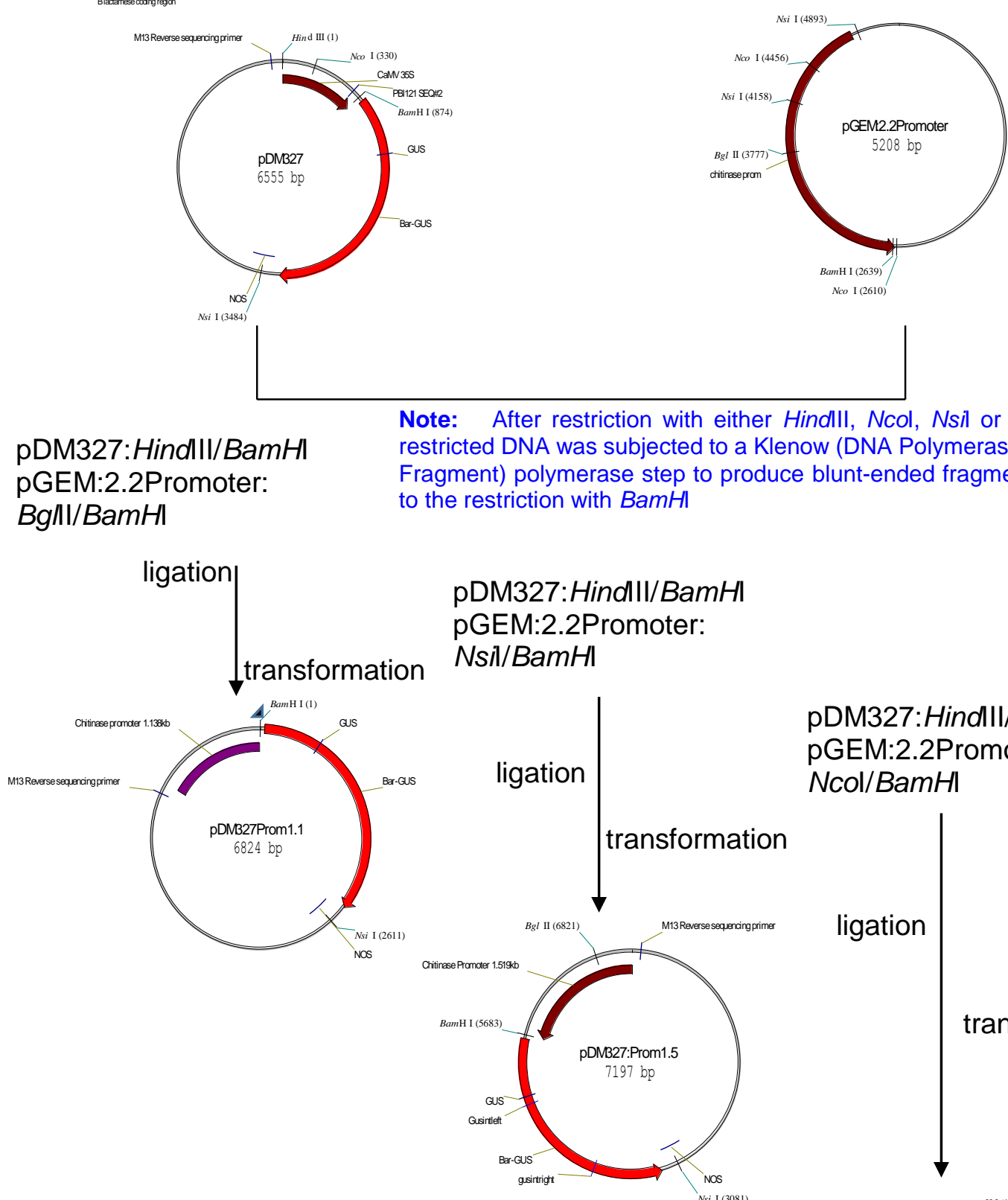

pDM327:HindII/BamHI pGEM:2.2Promoter: $\mathrm{Ncol} / \mathrm{BamH}$

Figure S4: Strategy for cloning the 3 class-III chitinase (if3) promoter-containing fragments $(1.138 \mathrm{~kb}, 1.519 \mathrm{~kb}$ and $1.817 \mathrm{~kb})$ upstream from the bar-uidA (gus) gene in pDM327 (Kamo et al., 2000) for Biolistic ${ }^{\mathrm{TM}}$ transformation experiments to test for

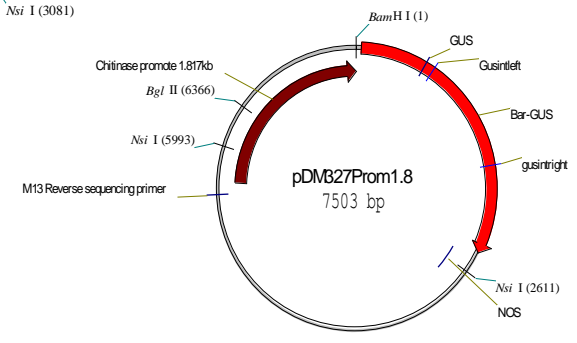
promoter activity in various plant tissues. 